\title{
Total Energy Intake and Self-Selected Macronutrient Distribution During Wildland Fire Suppression
}

\author{
Alexander N. Marks, MS ${ }^{1}$; Joseph A. Sol, $\mathrm{MS}^{2}$; Joseph W. Domitrovich, $\mathrm{PhD}^{2}$; \\ Molly R. West, $\mathrm{MPH}^{3}$; Brent C. Ruby, $\mathrm{PhD}^{1}$ \\ ${ }^{1}$ Montana Center for Work Physiology and Exercise Metabolism, University of Montana, Missoula, MT; ${ }^{2}$ National Technology and Development Pro- \\ gram, United States Department of Agriculture Forest Service, Missoula, MT; ${ }^{3}$ School of Public Health, University of California, Berkeley, Berkeley, CA
}

\begin{abstract}
Introduction - Wildland firefighters (WLFF) work long hours in extreme environments, resulting in high daily total energy expenditure. Increasing work-shift eating episodes and/or providing rations that promote convenient eating has shown augmented self-selected work output, as has regular carbohydrate $(\mathrm{CHO})$ consumption. It remains unclear how current WLFF feeding strategies compare to more frequent nutrient delivery. Our aim was to determine WLFFs' self-selected field total energy intake (TEI), composition, and feeding patterns during wildland fire suppression shifts.

Methods-WLFF were deployed to fire incidents across the United States throughout the 2018 fire season. Preshift food inventories collected at basecamp provided item-specific nutrient content (kilocalories, $\mathrm{CHO}$, fat, protein). Work shift consumption (TEI, feeding frequency, episodic composition) was monitored in real time by field researchers on fireline via observational data capture using mobile tablets. Shift work output was also quantified via actigraph accelerometry.

Results-Eighty-six WLFF (27.5 \pm 6.4 y; 16 female, 70 male) worked $14.0 \pm 1.1 \mathrm{~h}$ shifts, with a TEI of $6.3 \pm 2.5 \mathrm{MJ}(1494 \pm 592 \mathrm{kcal})(51 \pm 10,37 \pm 9,13 \pm 4 \%$ for $\mathrm{CHO}$, fat, and protein, respectively). WLFF averaged $4.3 \pm 1.6$ eating episodes $\left(1.4 \pm 1.3 \mathrm{MJ}[345 \pm 306 \mathrm{kcal}]\right.$ and $44 \pm 38 \mathrm{~g} \mathrm{CHO} \cdot$ episode $\left.^{-1}\right)$. WLFF who consumed $>20 \mathrm{kcal} \cdot \mathrm{kg}^{-1}$ averaged less sedentary activity than those consuming $<16 \mathrm{kcal} \cdot \mathrm{kg}^{-1}$. Data are presented as mean $\pm \mathrm{SD}$.

Conclusions - Not including fire camp meals (breakfast, dinner), the present work-shift TEI approximates $33 \%$ of previously determined WLFF total energy expenditure and demonstrates that current WLFF consumption patterns may not deliver adequate nutrients for occupational demands.
\end{abstract}

Keywords: carbohydrate, field study, occupational physiology, performance monitoring, wildland firefighting

\section{Introduction}

Wildland firefighters (WLFF) are regularly exposed to myriad environmental and physical demands, including

Project presented via oral (American College of Sports Medicine Northwest Regional Conference in Bend, OR; March 2, 2019) and poster presentations (American College of Sports Medicine National Conference in Orlando, FL; May 28, 2019).

Corresponding author: Brent C. Ruby, PhD, Montana Center for Work Physiology and Exercise Metabolism, School of Integrative Physiology \& Athletic Training, University of Montana, McGill Hall, Missoula, MT 59812-1825; e-mail: brent.ruby@mso.umt.edu.

Submitted for publication August 2019.

Accepted for publication January 2020. extended work shifts ( $\leq 24 \mathrm{~h})$ in adverse conditions (heat, altitude, and low humidity), compromised diet, and sleep deprivation. ${ }^{1-4}$ The hardships of a fire assignment depend on the fire intensity, geographic location, and respective ambient conditions. Using doubly labeled water methodology, our laboratory previously determined the total energy expenditure (TEE) of the WLFF to be 11.4 to $26.2 \mathrm{MJ} \cdot \mathrm{d}^{-1}$ (2719-6260 kcal $\left.\cdot \mathrm{d}^{-1}\right){ }^{1}$ Fifteen years later, we reported a similar range of TEE $\left(12.3-25.5 \mathrm{MJ} \cdot \mathrm{d}^{-1}[2946-6083\right.$ $\left.\left.\mathrm{kcal} \cdot \mathrm{d}^{-1}\right]\right)$ with an average output of $19.1 \pm 3.9 \mathrm{MJ} \cdot \mathrm{d}^{-1}$ $\left(4556 \pm 943 \mathrm{kcal} \cdot \mathrm{d}^{-1}\right),{ }^{4}$ again demonstrating the arduous yet consistent nature of the WLFF profession.

Despite former promotion of high protein intake for individuals performing large amounts of work, it has 
more recently been established that diets primarily consisting of carbohydrates $(\mathrm{CHO})$ are advantageous to optimize total work output by those engaged in strenuous occupational or physical training. ${ }^{5-8}$ Previously reported nutritional records suggest that WLFF's total CHO intake in fire camps may be inadequate owing to the self-selection of foodstuffs containing dietary fat and protein quantities greater than those recommended for arduous work. ${ }^{1}$ Moreover, the timing of intake has shown improved maintenance of steady work output and prevention of gastrointestinal discomfort. ${ }^{9-13}$ Supplemental feedings during long-duration exercise $(>2$ h) have consistently demonstrated increased ability to complete physical work, ${ }^{7-26}$ a notion later confirmed by auxiliary feeding interventions that elicited improved work output during latter work-shift hours. ${ }^{27}$ Additionally, our laboratory demonstrated significant muscle glycogen preservation in males and females when $\mathrm{CHO}$ was regularly supplied during a $10 \mathrm{~h}$ exercise trial. ${ }^{25}$ Enhanced work performance was further indicated via supplemental consumption by way of augmented episodic frequency using a redesigned military ration system (first-strike ration). ${ }^{28}$

The occupational requirements of WLFF necessitate consumption of foods that meet energy demands and impart adequate satisfaction to sustain consumption patterns for the entirety of work shifts, which can last for up to $24 \mathrm{~h}$, and the fire season duration, typically extending from April to October. Currently provided WLFF work-shift rations are composed of a sack lunch of approximately 5.4 to $8.4 \mathrm{MJ}(1300-2000 \mathrm{kcal}),{ }^{29}$ although it is not well established whether this provides sufficient energy to maintain required work efforts. Furthermore, it remains uncertain whether current sack lunch provisions and packaging promote apposite feeding frequency. The aims of the present study, therefore, were to ascertain the average caloric and macronutrient (CHO, fat, protein) intake and distribution of all work-shift foods, as well as WLFF feeding behavior and corresponding work output throughout extended fire suppression shifts.

\section{Methods}

\section{PARTICIPANTS}

Participants deployed to 12 different wildland fire incidents across 6 regions of the western United States during the 2018 fire season were eligible for study participation. On the basis of their fire assignments, participants were recruited and enrolled by volunteer self-selection the night before the observed work shift. Prospective participants must have been deployed to fire incident for at least 1 complete day before study involvement to ensure having consumed at least a full day's worth of fire camp and line meals. Before study participation, participants provided written, informed consent by signing a university-approved institutional review board consent form, after which participant data (anthropometrics: height, body weight; and demographics: age, sex, location) were documented.

\section{WORK-SHIFT FOOD INVENTORY}

A complete inventory of all work-shift food items was conducted via manual and photographic data capture ${ }^{30-33}$ before leaving base camp (preshift food inventory), after which all registered food items were entered into a mobile tablet for ensuing work-shift observation. Caloric and macronutrient profiles of all inventoried foods were later catalogued in Food Processor Nutrition Analysis Software 11.1 (ESHA Research, Salem, OR) for future evaluation.

\section{FIELD CONSUMPTION}

All members of the research field team were detailed from current WLFF crews and trained in mobile tablet program manipulation and data capture at the United States Department of Agriculture Forest Service National Technology \& Development Program office in Missoula, Montana, before any data collection at the beginning of the fire season. Field research members' prior experience working as WLFF improved the reliability of their data collection efforts because their familiarity with the context and occupational setting enabled them to monitor participant field behavior with minimal influence or interruption.

Each day, 1 research team member was assigned to a WLFF (1:1) and used a previously compiled mobile tablet inventory approach to surveil and record feeding habits (food items consumed, amount and corresponding time of respective item intake) in real time throughout the work shift, thus minimizing the potential for recall or self-report inaccuracies. ${ }^{1,34-39}$ Alignment of previously inventoried foods' nutritional information with work-shift consumption observations enabled subsequent chronologic determination of caloric and macronutrient profiles of all individually consumed items and the average intake and distribution throughout the work shift and per feeding episode. For analytical purposes, a "feeding episode" was defined as any work-shift period during which intake of all foods occurred, with no more than $10 \mathrm{~min}$ elapsed between items consumed.

\section{ACTIGRAPHY}

Actical actigraphy units (MiniMitter, Bend, OR) were used to determine participant total body activity and movement while on shift. Monitors were distributed to participants on the morning of observation; to protect against damage 
and ensure stable positioning, monitors were secured on a white foam core square and placed in left chest pocket of participants' Nomex fire shirt. Unit placement was standardized for all data collection owing to WLFFs' frequent use of the upper body to perform daily job duties, thus providing the greatest likely capture of work performed. ${ }^{27,28,40} \mathrm{In}$ accordance with previous studies, per-minute activity counts were classified into distinct ranges (sedentary $[\leq 99$ counts $\cdot \mathrm{min}^{-1}$ ], light $\left[100-1499\right.$ counts $\left.\cdot \min ^{-1}\right]$, and moderate/vigorous $\left[\geq 1500\right.$ counts $\left.\cdot \mathrm{min}^{-1}\right]$ ), allowing for subsequent analysis of various work-shift intensities. ${ }^{27,28}$ For comparative intake analysis, work-shift consumption was examined in relation to participant body mass $\left(\mathrm{kcal} \cdot \mathrm{kg}^{-1}\right)$ and divided into subcategories (low, <16; medium, 16-20; and high, $>20$ ).

\section{STATISTICS}

One hundred twenty-five participants from various WLFF crew types volunteered for work-shift observation. If, on the day of study participation, participants did not complete a full work shift owing to reassignment or spike camping, consume all meals provided per current catering contract, or have all foods consumed during shift captured in both preshift food inventory and mobile tablet (ie, data loss), they were excluded from further analysis. Such exclusions resulted in a final pool of 86 WLFF participants for dietary and feeding assessment. Actigraphy examination necessitated additional exclusions because of data loss, yielding 74 WLFF participants for subsequent analyses of workshift activity.

All analyses were performed using Microsoft Excel 2016 (Microsoft, Seattle, WA) and R (R Core Team, Vienna, Austria). All descriptive data are presented as mean \pm SD. Independent $t$-tests were performed to examine sex-based differences among anthropometric measures and work-shift observations (consumption, activity). A 1-way analysis of variance was used to explore differences in

Table 1. WLFF demographic and work-shift demographic characteristics

\begin{tabular}{clll}
\hline Characteristics & Overall & Female & Male \\
\hline Participant (n) & 86 & 16 & 70 \\
Age (y) & $27.5 \pm 6.4$ & $25.8 \pm 5.1$ & $27.9 \pm 6.6$ \\
Height (cm) & $179 \pm 9$ & $166 \pm 7$ & $182 \pm 7^{\text {a }}$ \\
Weight (kg) & $81.3 \pm 15.9$ & $63.5 \pm 7.9$ & $85.4 \pm 14.4^{\mathrm{a}}$ \\
Shift & & & \\
Duration (h) & $14.0 \pm 1.1$ & $14.2 \pm 0.6$ & $14.0 \pm 1.2$ \\
Start time & $0616 \pm 35 \mathrm{~min}$ & & \\
End time & $2017 \pm 51 \mathrm{~min}$ & & \\
\hline
\end{tabular}

WLFF, wildland firefighters.

${ }^{a} P<0.05$ vs female.
Table 2. Caloric, macronutrient, and electrolyte composition of consumed fire camp meals and estimated daily totals

\begin{tabular}{llll}
\hline & Breakfast & Dinner & EDT \\
\hline Kilocalories & $878 \pm 352$ & $1312 \pm 550$ & $3684 \pm 1493$ \\
Carbohydrates $(\mathrm{g})$ & $100 \pm 55$ & $144 \pm 75$ & $434 \pm 214$ \\
Fat $(\mathrm{g})$ & $40 \pm 20$ & $53 \pm 32$ & $155 \pm 82$ \\
Protein $(\mathrm{g})$ & $32 \pm 13$ & $66 \pm 33$ & $147 \pm 68$ \\
Sodium $(\mathrm{mg})$ & $1685 \pm 1353$ & $2411 \pm 1028$ & $6513 \pm 3555$ \\
Potassium $(\mathrm{mg})$ & $1078 \pm 495$ & $1410 \pm 697$ & $3810 \pm 2056$ \\
\hline
\end{tabular}

EDT, estimated daily total (sum of total work shift provision and fire camp consumption).

work-shift activity, feeding episodes, caloric intake per kilogram body weight, and other behavioral and consumption metrics. Statistical significance is indicated by $\mathrm{P}$ values $<0.05$.

\section{Results}

\section{PARTICIPANTS}

Among all participants $(27.5 \pm 6.4 \mathrm{y})$, a difference in height and body weight between females and males was observed $(P<0.05)$ (Table 1).

\section{WORK SHIFT FEEDING}

WLFF work shift duration was $14.0 \pm 1.1 \mathrm{~h}$ with a total energy intake (TEI) of $6.3 \pm 2.5 \mathrm{MJ}(1494 \pm 592 \mathrm{kcal})$ and

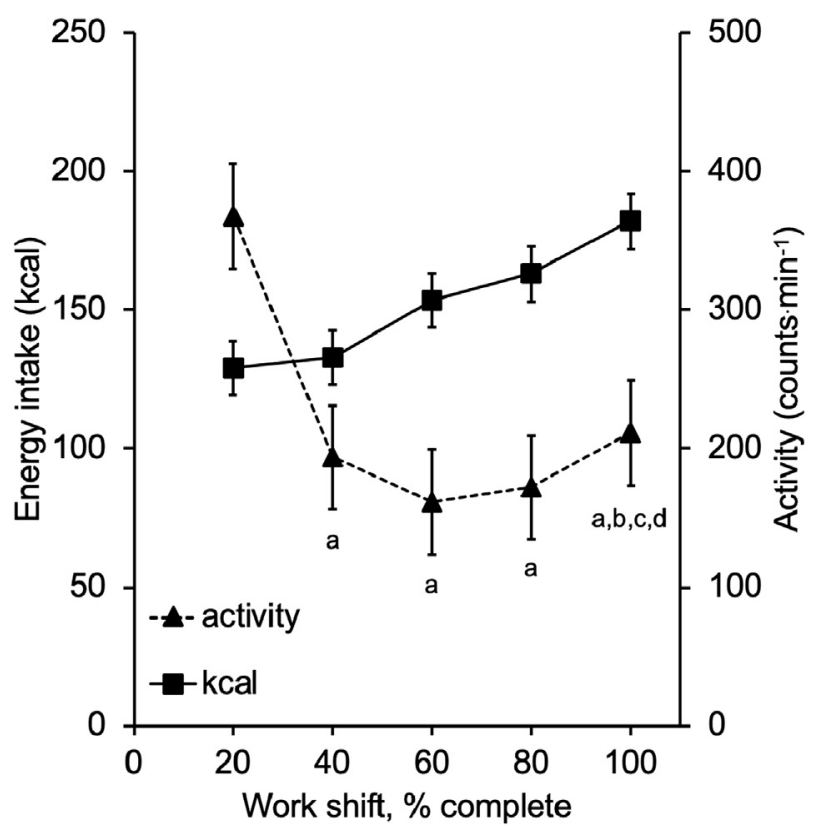

Figure 1. Caloric consumption and activity during wildland fire suppression shifts (mean \pm SEM). A, $P<0.05$ vs $20 \%$ work shift; $b$, $P<0.05$ vs $40 \%$ work shift; c, $P<0.05$ vs $60 \%$ work shift; d, $P<0.05$ vs $80 \%$ work shift. 
distribution of $51 \pm 10 \%, 37 \pm 9 \%$, and $13 \pm 4 \%$ for $\mathrm{CHO}$, fat, and protein, respectively. Additionally, respective sodium and potassium consumption were quantified as $2417 \pm$ 1174 and $1323 \pm 864 \mathrm{mg}$. Breakfast and dinner consumption was similarly measured and resulted in an estimated daily total consumption of $15.4 \pm 6.3 \mathrm{MJ} \cdot \mathrm{d}^{-1}(3684 \pm 1493$ $\mathrm{kcal} \cdot \mathrm{d}^{-1}$ ) (Table 2). Total caloric intake was lowest and greatest during the first and third quintiles of the work shift, respectively $(P<0.05)$. Conversely, average energy intake was shown to steadily rise throughout the work shift (Figure 1), during which the number of eating episodes ranged from 2 to 9.

Females exhibited a greater $\mathrm{CHO}$ intake, both as a percent of total caloric intake and per kilogram body weight, as well as consistently lower protein and sodium intake than their male counterparts (Table 3). Although no relationship was determined $(P=0.0506)$, males undertook fewer feeding episodes than did females throughout the work shift, during which there was a greater intake of calories, fat, and protein per episode (Table 4).

\section{ACTIGRAPHY}

For 74 of the 86 participants, $689 \pm 73$ min of activity was noted throughout the work shift. Overall work-shift activity was $220 \pm 168$ counts $\cdot \min ^{-1}$ and was composed of $63 \pm$ $17 \%, 33 \pm 17 \%$, and $4 \pm 5 \%$ sedentary, light, and moderate/ vigorous intensity, respectively. Activity counts exhibited a nearly $50 \%$ decrease from the first to third quintiles of the work shift, before slightly increasing over the latter quintiles (Figure 1), likely representing the ingress and egress hike to and from the fire line. Examination of episodic feeding frequency did not show a relationship with

Table 3. Total caloric, macronutrient, and electrolyte intake and distribution during wildland fire suppression shifts

\begin{tabular}{clll}
\hline & Overall & $\begin{array}{l}\text { Female } \\
(n=16)\end{array}$ & $\begin{array}{l}\text { Male } \\
(n=70)\end{array}$ \\
\hline Kilocalories (kcal) & $1494 \pm 592$ & $1392 \pm 412$ & $1518 \pm 626$ \\
$\mathrm{~kg}^{-1}$ & $191 \pm 8$ & $22 \pm 7$ & $18 \pm 8$ \\
Carbohydrates (g) & $191 \pm 84$ & $196 \pm 62$ & $189 \pm 89$ \\
$\mathrm{~kg}^{-1}$ & $2 \pm 1$ & $3 \pm 1$ & $2 \pm 1^{\mathrm{a}}$ \\
$\%$ kcal & $51 \pm 10$ & $57 \pm 10$ & $50 \pm 10^{\mathrm{a}}$ \\
Fat (g) & $61 \pm 30$ & $55 \pm 26$ & $62.8 \pm 30.6$ \\
$\mathrm{~kg}^{-1}$ & $0.8 \pm 0.4$ & $0.9 \pm 0.4$ & $0.8 \pm 0.4$ \\
$\%$ kcal & $37 \pm 8$ & $35 \pm 10$ & $37 \pm 9$ \\
Protein (g) & $49 \pm 22$ & $38 \pm 14$ & $52 \pm 2$ \\
$\mathrm{~kg}^{-1}$ & $0.6 \pm 2.0$ & $0.6 \pm 0.2$ & $0.6 \pm 0.3$ \\
$\%$ kcal & $13 \pm 4$ & $11 \pm 4$ & $14 \pm 4^{\mathrm{a}}$ \\
Sodium (mg) & $2417 \pm 1174$ & $1175 \pm 573$ & $2563 \pm 1229^{\mathrm{a}}$ \\
Potassium (mg) & $1323 \pm 864$ & $1594 \pm 787$ & $1260 \pm 874$ \\
\hline
\end{tabular}

${ }^{\mathrm{a}} P<0.05$ vs female.
Table 4. Episodic consumption and distribution during wildland fire suppression shifts

\begin{tabular}{llll}
\hline & Overall & $\begin{array}{l}\text { Female } \\
(n=16)\end{array}$ & $\begin{array}{l}\text { Male } \\
(n=70)\end{array}$ \\
\hline $\begin{array}{c}\text { Observed feeding } \\
\text { episodes }\end{array}$ & $4 \pm 1$ & $5 \pm 2$ & $4 \pm 2$ \\
$\begin{array}{c}\text { Interval between } \\
\text { episodes (min) }\end{array}$ & $117 \pm 76$ & $126 \pm 47$ & $133 \pm 50$ \\
$\quad$ Kilocalories & $345 \pm 307$ & $275 \pm 194$ & $364 \pm 329^{\mathrm{a}}$ \\
Carbohydrates (g) & $44 \pm 38$ & $39 \pm 27$ & $45 \pm 41$ \\
Fat (g) & $14 \pm 16$ & $11 \pm 11$ & $15 \pm 17^{\mathrm{a}}$ \\
Protein (g) & $11 \pm 13$ & $8 \pm 8$ & $12 \pm 14^{\mathrm{a}}$ \\
\hline
\end{tabular}

${ }^{\text {a }} P<0.05$ vs female.

average work shift activity $(P>0.05)$. There was a noted difference in the amount of moderate/vigorous activity performed $\left(41 \pm 32\right.$ vs $24 \pm 31$ counts $\cdot \min ^{-1}$ and $6 \pm 4 \%$ vs $4 \pm$ $5 \%$ for females and males, respectively; $P<0.05$ ); however, no differences were seen between the sexes in output of sedentary or light-intensity work.

Observed caloric intake per kilogram body weight was stratified into groups of equal proportion $(<16,16-20$, and $>20 \mathrm{kcal} \cdot \mathrm{kg}^{-1}$, respectively) for further analysis. Although caloric intake per kilogram body weight and work-shift activity counts were not statistically associated, subsequent contrast of work intensity did elicit a relationship $(P<0.05)$. WLFF who consumed greater than 20 $\mathrm{kcal} \cdot \mathrm{kg}^{-1}$ spent more of their individual work shifts (percent, total minutes) performing light intensity work $\left(100-1499\right.$ counts $\left.\cdot \min ^{-1}\right)$ than sedentary activity $(\leq 99$ counts $\cdot \min ^{-1}$ ) (Table 5). No associations between caloric intake per kilogram body weight and moderate/vigorousintensity work $\left(\geq 1500\right.$ counts $\left.\cdot \mathrm{min}^{-1}\right)$ were observed among any of the groups. A difference was observed

Table 5. Total energy intake relative to body mass $\left(\mathrm{kcal} \cdot \mathrm{kg}^{-1}\right)$ and the differences in self-selected work output distribution.

\begin{tabular}{llll}
\hline & $\begin{array}{l}<16 \\
\mathrm{kcal} \cdot \mathrm{kg}^{-1}\end{array}$ & $\begin{array}{l}16-20 \\
\mathrm{kcal} \cdot \mathrm{kg}^{-1}\end{array}$ & $\begin{array}{l}>20 \\
\mathrm{kcal} \cdot \mathrm{kg}^{-1}\end{array}$ \\
\hline $\begin{array}{c}\text { Average activity } \\
\left(\text { counts } \cdot \mathrm{min}^{-1}\right)\end{array}$ & $196 \pm 150$ & $220 \pm 192$ & $246 \pm 165$ \\
Sedentary (min) & $463 \pm 77$ & $446 \pm 129$ & $388 \pm 150^{\mathrm{a}}$ \\
Sedentary (\%) & $68 \pm 11$ & $66 \pm 18$ & $56 \pm 20^{\mathrm{a}}$ \\
Light (min) & $195 \pm 82$ & $205 \pm 116$ & $284 \pm 153^{\mathrm{a}}$ \\
Light $(\%)$ & $28 \pm 11$ & $30 \pm 17$ & $40 \pm 20^{\mathrm{a}}$ \\
Moderate/ & $28 \pm 30$ & $28 \pm 37$ & $28 \pm 29$ \\
$\quad$ Vigorous (min) & & & \\
Moderate/ & $4 \pm 5$ & $4 \pm 6$ & $4 \pm 4$ \\
$\quad$ Vigorous $(\%)$ & & & \\
\hline a P<0.05 vs $<16 \mathrm{kcal} \cdot \mathrm{kg}^{-1}$. & &
\end{tabular}


between work-shift feeding episode count per group $(<16$ and $>20 \mathrm{kcal} \cdot \mathrm{kg}^{-1}$, respectively; $P<0.05$ ).

\section{Discussion}

WLFF are routinely subjected to unfavorable and potentially injurious conditions (rough terrain, acute altitude, low humidity, high ambient and radiant heat $)^{41-43}$ during extended work shifts. Ingress hikes to the fire line have demonstrated the greatest metabolic demand during fire suppression shifts, ${ }^{44}$ which often emphasize greater need for long-term endurance than high-intensity efforts. ${ }^{45}$ Previous base camp nutritional records have evinced greater-than-advised fat and protein consumption, ${ }^{1}$ despite recent promotion of diets rich in $\mathrm{CHO}$ for those performing great amounts of labor. ${ }^{5-8}$ It was recently indicated that WLFF incurred diminished health measurements over the duration of the fire season, ${ }^{46}$ namely increased total cholesterol and low-density lipoprotein and elevated total body and visceral fat. Intrahepatic lipid was also noted to trend upward at season's end, despite the lack of significant difference. Although these maladaptations cannot be fully attributed to deficient nutrient and fuel delivery throughout the fire season, they may suggest ramifications of the seasonal lifestyle alterations and arduous occupational demands of WLFF.

Improved feeding occurrence has also demonstrated efficacy in minimizing gastrointestinal distress while maintaining steady work output over training or work periods of $2+\mathrm{h},{ }^{7-26}$ and our laboratory has illustrated preservation of muscle glycogen via regular $\mathrm{CHO}$ ingestion during prolonged exercise. ${ }^{25}$ Ancillary work shift feedings have also demonstrated enhanced WLFF occupational performance, especially in a shift's latter hours. ${ }^{27,28}$ Furthermore, we have shown that $8.2 \pm 1.3$ and 7.6 \pm 1.1 eating episodes for different sack lunch provisions (first-strike rations and meals ready-to-eat, respectively) during a 2-d ration intervention among actively deployed WLFF. ${ }^{28}$ Under similar observation, $64 \%$ of participants were noted to have eaten between 2 and 4 times throughout the work shift (Figure 2), despite heightened caloric and macronutrient consumption as a result of increased frequency of eating (Figure 3). Sex-based feeding differences (Tables 2 and 3) are also in line with our laboratory's previous findings. ${ }^{1}$ Potentially stemming from fire activity and corresponding shift duties or food item-specific packaging, discrepancies between observed feeding episodes may have a direct effect on self-selected feeding behaviors. It is imperative that WLFF and those in comparable prolonged-performance occupations (eg, military personnel) have reliable access to appropriate shift

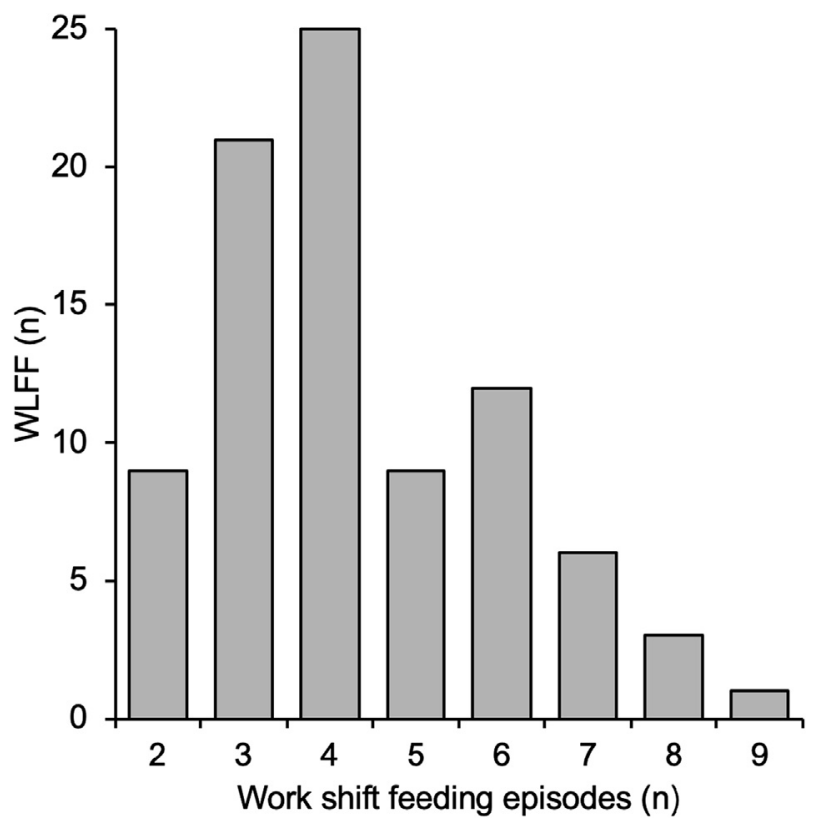

Figure 2. Observed feeding episodes during wildland fire suppression shift; $\mathrm{n}=86$.

provisions to ensure acceptable work output and minimize safety risks.

WLFF work tasks require foods that provide sufficient energy for the duration of the shift. The peak total consumption observed during the middle of the shift likely indicates the typical "lunch break" that may be practiced by some crews. Although average caloric intake was noted to steadily increase over the course of the work shift (Figure 1), fat and protein constituted a greater percentage of the overall composition as the shift progressed (Figure 4). Accordingly, the majority of the work shift was spent performing sedentary or light activity (Figure 5), which is comparable to previous findings from our laboratory that demonstrate increased work demands associated with ingress and egress hikes to and from the fire line in the work shift's bookend hours. ${ }^{4,44}$ Actigraphy data from our prior studies exhibited higher work rates $\left(335 \pm 218\right.$ and $338 \pm 83$ counts $\cdot \mathrm{min}^{-1}$, respectively $)^{27,28}$ compared to values in the present study $\left(220 \pm 168\right.$ counts $\left.\cdot \mathrm{min}^{-1}\right)$.

As indicated by standing interagency policies, National Wildfire Coordinating Group fire resource crews typically adhere to standard 14-d deployments throughout a nearly 6-mo fire season. Contemporary WLFF work shift provisions include an isocaloric sack lunch ${ }^{29}$ that is often supplemented with more favorable/preferred food items. Roughly $78 \%$ of WLFF participants were noted to have consumed accessory food items (ie, not provided in the caterer-supplied sack lunch), which ultimately accounted for $32 \%$ of 
A

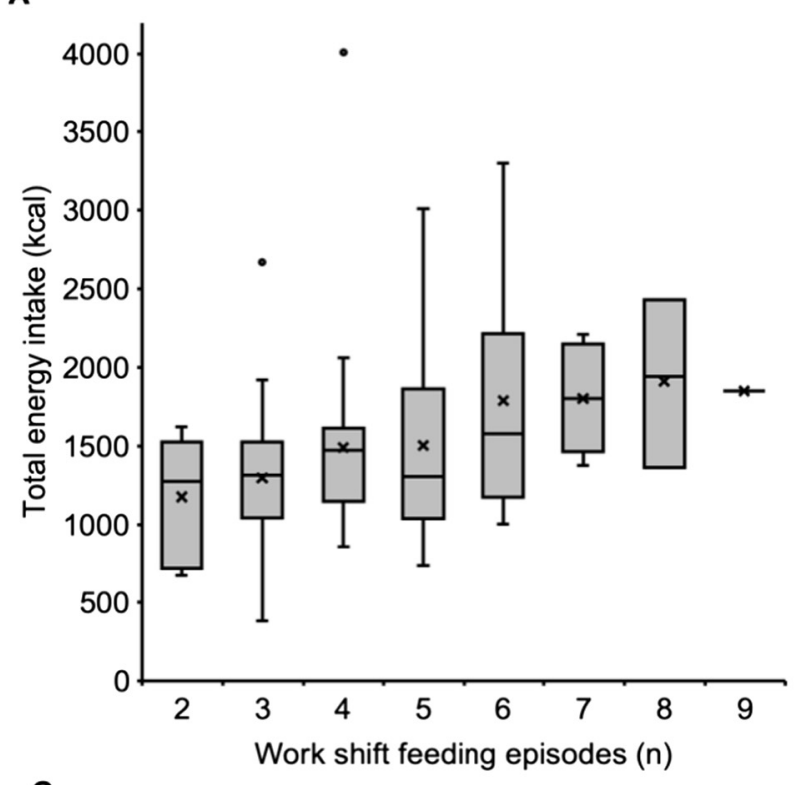

C

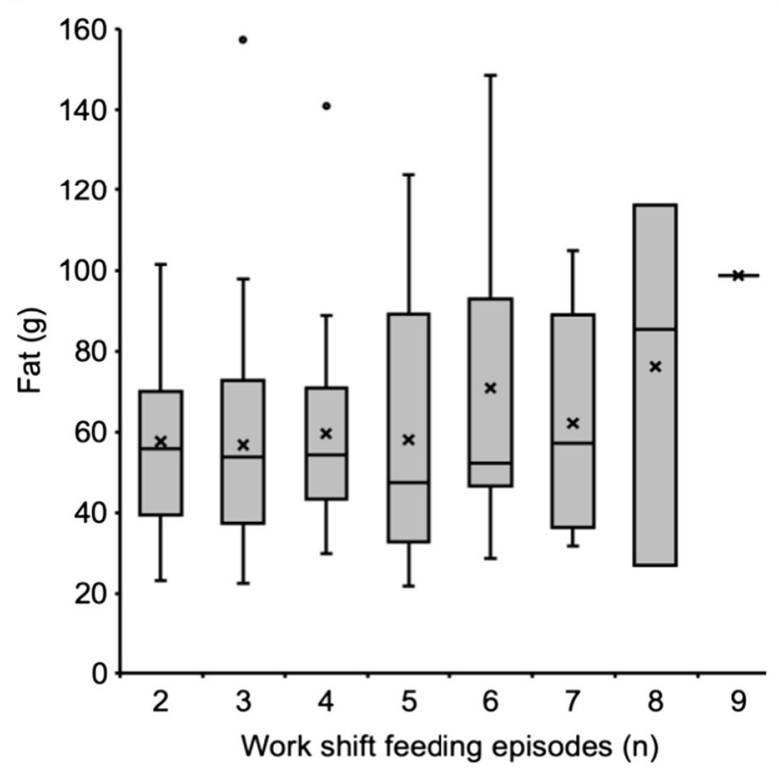

B

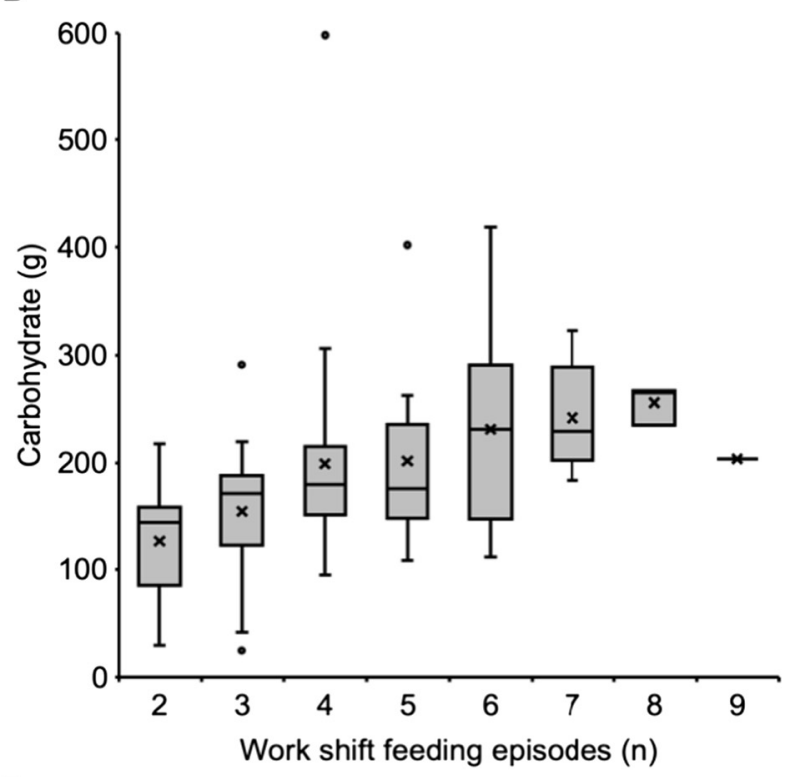

D

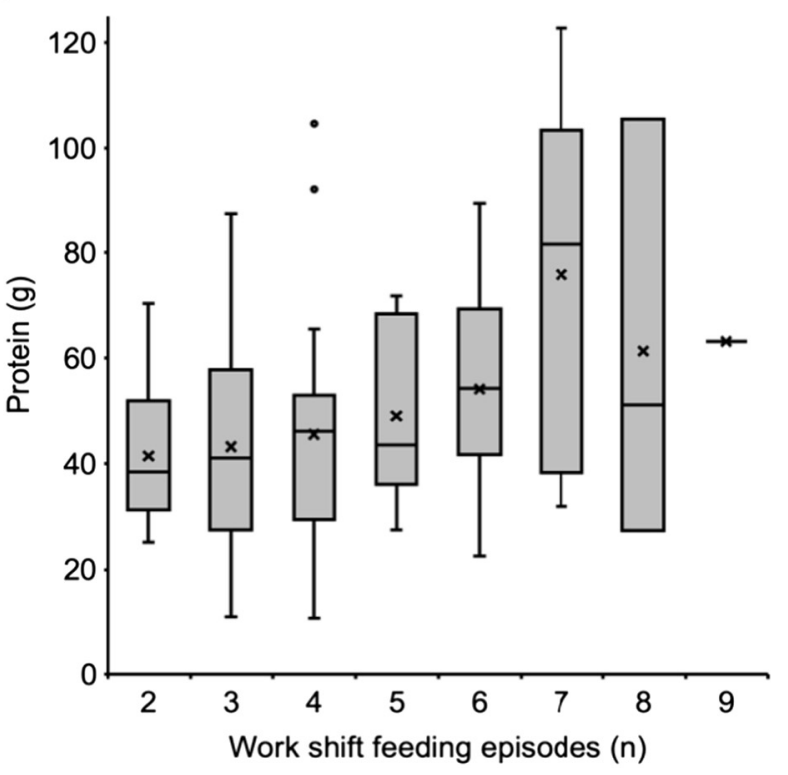

Figure 3. Caloric consumption (A) and macronutrient distribution (B-D) relative to eating episodes during wildland fire suppression shifts.

their respective work shift calories. Furthermore, $72 \pm 38 \%$ of the calories WLFF took with them for the day, including catering provisions and supplemental foods, were noted to have been consumed during the shift. Although it has not previously been established whether shift rations currently provide adequate energy to maintain required work efforts or promote optimal feeding incidence, our results ultimately indicate that work-shift TEI supplies roughly $33 \%$ of the previously observed TEE $\left(19.1 \pm 3.9 \mathrm{MJ} \cdot \mathrm{d}^{-1}[4556 \pm 943\right.$ $\left.\mathrm{kcal} \cdot \mathrm{d}^{-1} \mathrm{j}\right),{ }^{4}$ revealing a substantial disparity with WLFF's commonly elicited work-shift output. Threats to WLFF safety and performance may increase if undertaken acutely, especially in the shift's latter hours when fire behavior is often the least predictable and potentially volatile; however, season-long reliance on external fuel sources may elicit greater occurrence of negative energy balance if somehow unavailable (eg, financial or geographical limitations). Similarly, lack of dietary diversity may discourage appropriate work-shift feeding, consequently resulting in threats to seasonal energy balance preservation. Current standard fire orders highlight the importance of "fire line group and personal safety" and the need to "fight fire aggressively, 


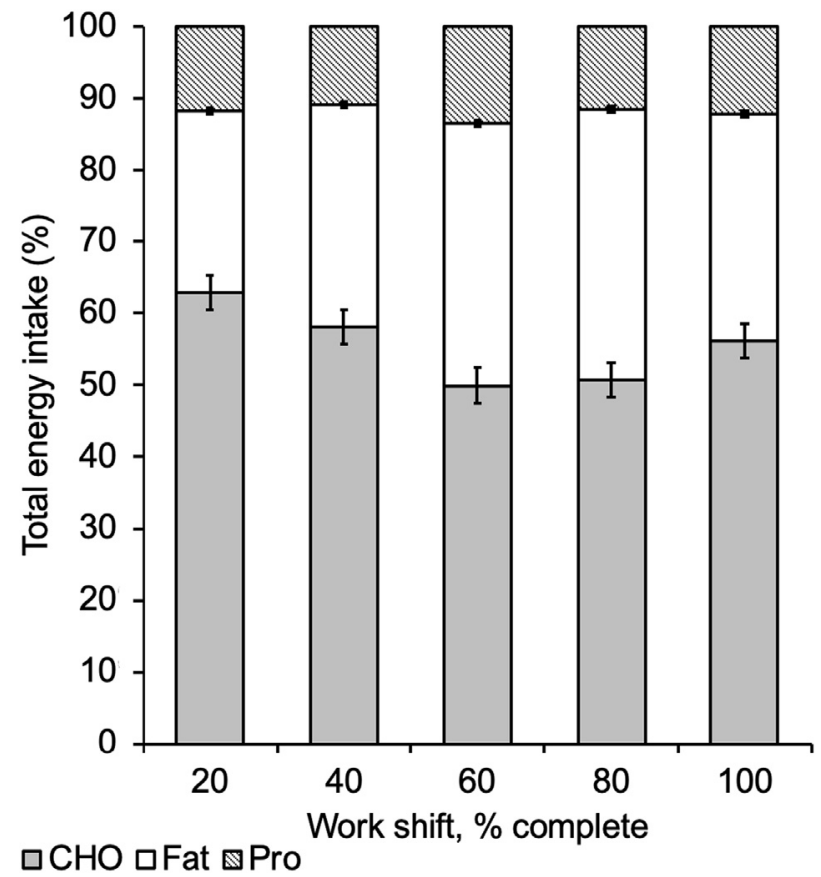

Figure 4. Wildland fire suppression work shift macronutrient composition.

having provided for safety first, ${ }^{47}$ and these data suggest that more aggressive fire suppression operations likely demand improved coordination of feeding frequency and availability of diverse provisions.

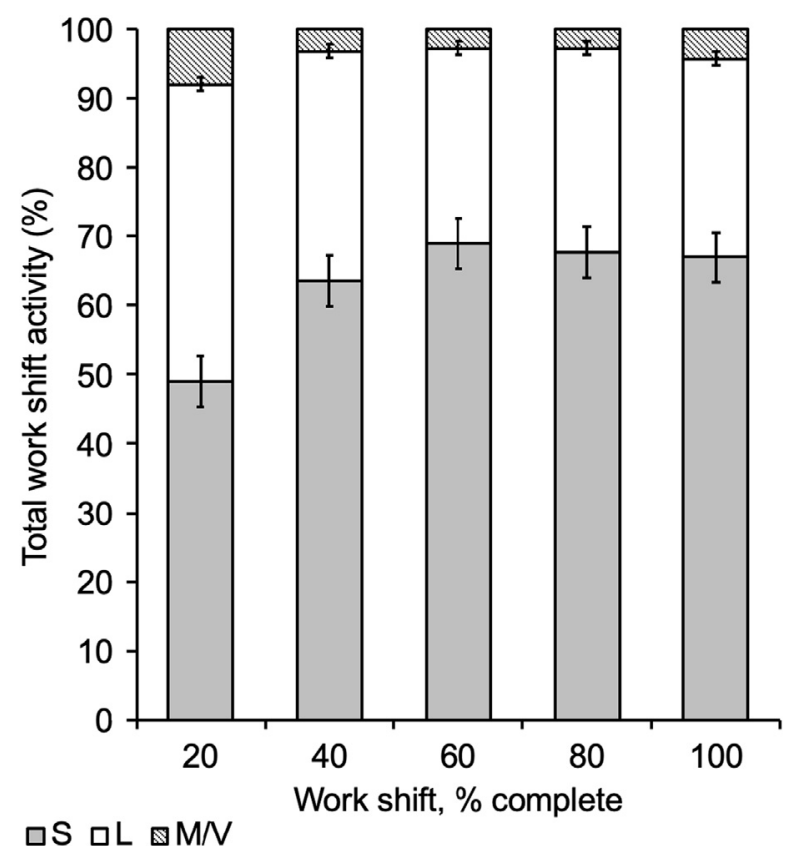

Figure 5. Wildland fire suppression work shift intensity composition (\% total activity); $\mathrm{S}=$ sedentary $\left(\leq 99\right.$ counts $\left.\cdot \mathrm{min}^{-1}\right), \mathrm{L}=$ light $(100-1499$ counts $\left.\cdot \mathrm{min}^{-1}\right) ; \mathrm{M} / \mathrm{V}=$ moderate/vigorous $\left(\geq 1500\right.$ counts $\left.\cdot \mathrm{min}^{-1}\right)$.
This is the first study to appraise the free-living (ie, without intervention) feeding habits of WLFF during unscripted fire suppression work shifts. The techniques used to monitor behavior did not rely on individual recall or self-report, as has historically been a hindrance of dietary and nutritional data collection, ${ }^{1,34-39}$ thus imparting improved reporting accuracy. Although researchers following WLFF throughout their shift may have engendered unnatural feeding behavior, all members of the study team also worked as fire line personnel and were thus fit to minimize interruption of WLFF habitual feeding and activity. The greatest limitation, therefore, is likely the inconsistency of specific work-shift tasks owing to the varying fire activity and conditions inherent to the WLFF position.

\section{Conclusions}

Current WLFF feeding practices and rations likely do not provide sufficient fuel consummate with labor assignments, as indicated by the noted discrepancy between our laboratory's TEE ${ }^{1,4}$ and TEI findings. Present data also provide an association between relative energy intake $\left(\mathrm{kcal} \cdot \mathrm{kg}^{-1}\right)$ and self-selected work activity. Moreover, work shift feeding episodes were shown to influence relative consumption $\left(\mathrm{kcal} \cdot \mathrm{kg}^{-1}\right)$, although no relationship was observed between feeding frequency and work output, perhaps owing to insufficient statistical power within our participant pool. Future studies should therefore seek to determine optimal nutrition delivery and ideal dietary diversity to sustain appropriate intake for the duration of the fire season. Further explication of the influences of work shift provisions on overall patterns of self-selected work output should also lead to development of optimal work-shift rationing to encourage requisite consumption.

Acknowledgments: The authors thank all fire crews for their volunteer efforts; the field research team of Logan Fisher, Molly West, Tim LaRoche, and Zane Cuthill for their meticulous efforts in collecting all work-shift data; and John Cuddy for his assistance in analyzing activity data.

Author Contributions: Study concept and design (JAS, JWD, BCR); obtaining funding (JAS, JWD); data acquisition (JAS, MRW); data analysis (ANM); drafting of the manuscript (ANM, BCR); critical revision of the manuscript (BCR); approval of final manuscript (BCR)

Financial/Material Support: Support provided by National Technology \& Development Program, United States Department of Agriculture, Forest Service.

Disclosures: None.

\section{References}

1. Ruby BC, Shriver TC, Zderic TW, Sharkey BJ, Burks C, Tysk S. Total energy expenditure during arduous wildfire suppression. Med Sci Sports Exerc. 2002;34(6):1048-54. 
2. Heil DP. Estimating energy expenditure in wildland fire fighters using a physical activity monitor. Appl Ergon. 2002;33(5): 405-13.

3. Ruby BC, Schoeller DA, Sharkey BJ, Burks C, Tysk S. Water turnover and changes in body composition during arduous wildfire suppression. Med Sci Sports Exerc. 2003;35(10): 1760-5.

4. Cuddy JS, Sol JA, Hailes WS, Ruby BC. Work patterns dictate energy demands and thermal strain during wildland firefighting. Wilderness Environ Med. 2015;26(2):221-6.

5. Jeukendrup AE. Carbohydrate intake during exercise and performance. Nutrition. 2004;20(7-8):669-77.

6. Bosch AN, Noakes TD. Carbohydrate ingestion during exercise and endurance performance. Indian $J$ Med Res. 2005;121(5):634-8.

7. Montain SJ, Shippee RL, Tharion WJ. Carbohydrate-electrolyte solution effects on physical performance of military tasks. Aviat Space Environ Med. 1997;68(5):384-91.

8. Montain SJ, Young AJ. Diet and physical performance. Appetite. 2003;40(3):255-67.

9. Fielding RA, Costill DL, Fink WJ, King DS, Hargreaves M, Kovaleski JE. Effect of carbohydrate feeding frequencies and dosage on muscle glycogen use during exercise. Med Sci Sports Exerc. 1985;17(4):472-6.

10. Coggan AR, Coyle EF. Reversal of fatigue during prolonged exercise by carbohydrate infusion or ingestion. J Appl Physiol (1985). 1987;63(6):2388-95.

11. Wright DA, Sherman WM, Dernbach AR. Carbohydrate feedings before, during, or in combination improve cycling endurance performance. J Appl Physiol (1985). 1991;71(3): 1082-8.

12. McConell G, Kloot K, Hargreaves M. Effect of timing of carbohydrate ingestion on endurance exercise performance. Med Sci Sports Exerc. 1996;28(10):1300-4.

13. Febbraio MA, Chiu A, Angus DJ, Arkinstall MJ, Hawley JA. Effects of carbohydrate ingestion before and during exercise on glucose kinetics and performance. J Appl Physiol (1985). 2000;89(6):2220-6.

14. Carter J, Jeukendrup AE, Mundel T, Jones DA. Carbohydrate supplementation improves moderate and high-intensity exercise in the heat. Pflugers Arch. 2003;446(2):211-9.

15. Byrne C, Lim CL, Chew SAN, Ming ETY. Water versus carbohydrate-electrolyte fluid replacement during loaded marching under heat stress. Mil Med. 2005;170(8):715-21.

16. Ivy JL, Miller W, Dover V, Goodyear LG, Sherman WM, Farrell S, et al. Endurance improved by ingestion of a glucose polymer supplement. Med Sci Sports Exerc. 1983;15(6): 466-71.

17. Coyle EF, Hagberg JM, Hurley BF, Martin WH, Ehsani AA, Holloszy JO. Carbohydrate feeding during prolonged strenuous exercise can delay fatigue. J Appl Physiol Respir Environ Exerc Physiol. 1983;55(1 Pt 1):230-5.

18. Hargreaves M, Costill DL, Coggan A, Fink WJ, Nishibata I. Effect of carbohydrate feedings on muscle glycogen utilization and exercise performance. Med Sci Sports Exerc. 1984;16(3):219-22.

19. Coyle EF, Coggan AR, Hemmert MK, Ivy JL. Muscle glycogen utilization during prolonged strenuous exercise when fed carbohydrate. J Appl Physiol (1985). 1986;61(1):165-72.

20. Langenfeld ME, Seifert JG, Rudge SR, Bucher RJ. Effect of carbohydrate ingestion on performance of non-fasted cyclists during a simulated 80-mile time trial. J Sports Med Phys Fitness. 1994;34(3):263-70.

21. Tsintzas K, Liu R, Williams C, Campbell I, Gaitanos G. The effect of carbohydrate ingestion on performance during a 30-km race. Int J Sport Nutr. 1993;3(2):127-39.

22. Meyer T, Gabriel HHW, Auracher M, Scharhag J, Kindermann W. Metabolic profile of $4 \mathrm{~h}$ cycling in the field with varying amounts of carbohydrate supply. Eur J Appl Physiol. 2003;88(4-5):431-7.

23. Zaryski C, Smith DJ. Training principles and issues for ultra-endurance athletes. Curr Sports Med Rep. 2005;4(3): $165-70$.

24. Kruseman M, Bucher S, Bovard M, Kayser B, Bovier PA. Nutrient intake and performance during a mountain marathon: an observational study. Eur J Appl Physiol. 2005;94(1-2): 151-7.

25. Harger-Domitrovich SG, McClaughry AE, Gaskill SE, Ruby BC. Exogenous carbohydrate spares muscle glycogen in men and women during $10 \mathrm{~h}$ of exercise. Med Sci Sports Exerc. 2007;39(12):2171-9.

26. Thomas DT, Erdman KA, Burke LM. American College of Sports Medicine Joint Position Statement. Nutrition and Athletic Performance. Med Sci Sports Exerc. 2016;48(3): 543-68.

27. Cuddy JS, Gaskill SE, Sharkey BJ, Harger SG, Ruby BC. Supplemental feedings increase self-selected work output during wildfire suppression. Med Sci Sports Exerc. 2007;39(6):1004-12.

28. Montain SJ, Baker-Fulco CJ, Niro PJ, Reinert AR, Cuddy JS, Ruby BC. Efficacy of eat-on-move ration for sustaining physical activity, reaction time, and mood. Med Sci Sports Exerc. 2008;40(11):1970-6.

29. Robillard L. 2015-2019 National mobile food services contract. Available at: https://gacc.nifc.gov/swcc/dc/azpdc/ operations/documents/equipment/2015-2019_Mobile_Food_ Service_Contract.pdf. Accessed May 2019.

30. Illner A-K, Freisling H, Boeing H, Huybrechts I, Crispim SP, Slimani N. Review and evaluation of innovative technologies for measuring diet in nutritional epidemiology. Int J Epidemiol. 2012;41(4):1187-203.

31. Dorman SC, Gauthier AP, Laurence M, Thirkill L, Kabaroff JL. Photographic examination of student lunches in schools using the balanced school day versus traditional school day schedules. ICAN Infant Child Adolesc Nutr. 2013;5(2):78-84.

32. Gauthier AP, Jaunzarins BT, MacDougall S-J, Laurence M, Kabaroff JL, Godwin AA, et al. Evaluating the reliability of assessing home-packed food items using digital photographs and dietary log sheets. J Nutr Educ Behav. 2013;45(6): 708-12.

33. Martin CK, Nicklas T, Gunturk B, Correa JB, Allen HR, Champagne C. Measuring food intake with digital photography. J Hum Nutr Diet. 2014;27. Suppl 1(0 1): $72-81$. 
34. Lichtman SW, Pisarska K, Berman ER, Pestone M, Dowling $\mathrm{H}$, Offenbacher E, et al. Discrepancy between self-reported and actual caloric intake and exercise in obese subjects. N Engl J Med. 1992;327(27):1893-8.

35. Nelson M, Bingham SA. Assessment of food consumption and nutrient intake. In: Design Concepts in Nutritional Epidemiology. Oxford, UK: Oxford University Press; 1997.

36. Livingstone MBE, Black AE. Markers of the validity of reported energy intake. J Nutr. 2003;133(Suppl 3). S895-920.

37. Penn L, Boeing H, Boushey CJ, Dragsted LO, Kaput J, Scalbert A, et al. Assessment of dietary intake: NuGO symposium report. Genes Nutr. 2010;5(3):205-13.

38. Sharp DB, Allman-Farinelli M. Feasibility and validity of mobile phones to assess dietary intake. Nutrition. 2014;30(11-2):1257-66.

39. Pendergast FJ, Ridgers ND, Worsley A, McNaughton SA. Evaluation of a smartphone food diary application using objectively measured energy expenditure. Int J Behav Nutr Phys Act. 2017;14(1):30.

40. Heil DP, Ruby BC, Gaskill SE, Lankford E, Sharkey BJ. Prediction of energy expenditure during simulated wildland fire suppression tasks. Med Sci Sports Exerc. 2004;36(5):S219.
41. Cuddy JS, Ruby BC. High work output combined with high ambient temperatures caused heat exhaustion in a wildland firefighter despite high fluid intake. Wilderness Environ Med. 2011;22(2):122-5.

42. Lui B, Cuddy JS, Hailes WS, Ruby BC. Seasonal heat acclimatization in wildland firefighters. J Therm Biol. 2014;45: 134-40.

43. Hailes WS, Cuddy JS, Cochrane K, Ruby BC. Thermoregulation during extended exercise in the heat: comparisons of fluid volume and temperature. Wilderness Environ Med. 2016;27(3):386-92.

44. Sol JA, Ruby BC, Gaskill SE, Dumke CL, Domitrovich JW. Metabolic demand of hiking in wildland firefighting. Wilderness Environ Med. 2018;29(3):304-14.

45. Panter-Brick C. Issues of work intensity, pace, and sustainability in relation to work context and nutritional status. $A m$ J Hum Biol. 2003;15(4):498-513.

46. Coker RH, Murphy CJ, Johannsen M, Galvin G, Ruby BC. Wildland firefighting: Adverse influence on indices of metabolic and cardiovascular health. J Occup Environ Med. 2019;61(3):e91-4.

47. National Wildfire Coordinating Group. 10 standard fire orders | NWCG. Available at: https://www.nwcg.gov/committee/ 6mfs/10-standard-fire-orders. Accessed May 2019. 